\title{
CURRENT DEVELOPMENTS ON ANTI-INFLAMMATORY NATURAL MEDICINES
}

\author{
SAYANNA DAS, SUDIP KUMAR MANDAL*
}

Department of Pharmaceutical Chemistry, Dr. B. C. Roy College of Pharmacy and Allied Health Sciences, Durgapur - 713 206, West Bengal, India. Email: gotosudip79@gmail.com

Received: 07 April 2018, Revised and Accepted: 10 May 2018

ABSTRACT

New anti-inflammatory substances are still vitally necessary due to intolerable side effects of the marketed anti-inflammatory drugs; however, the search for the novel entity against inflammation is challenging because of the complexity of the inflammatory process and its role in host defense to infections. Nature is the source of remedies for the mankind. Among the different biological activities of natural products that have been published till date, anti-inflammation is one of the most reported effects. In this review, we have discussed the current (2009-2018) information of some single natural products (quercetin, parthenolide, resveratrol, curcumin, cucurbitacin, capsicin, 1,8-cineole, bromelain, boswellic acid, lyprinol, and coumarin), plant products (garlic, ginger, papaya, blueberry, aloe, broccoli, olive, and rosemary), and non-plant products (marine sponges, mushrooms, and honey) having anti-inflammatory effects. Current information is mainly based on the molecular mechanisms of the above-mentioned products.

Keywords: Single natural products, Plant products, Non-plant products, Anti-inflammatory activity, Molecular pharmacology.

(c) 2018 The Authors. Published by Innovare Academic Sciences Pvt Ltd. This is an open access article under the CC BY license (http://creativecommons. org/licenses/by/4. 0/) DOI: http://dx.doi.org/10.22159/ajpcr.2018.v11i8.26523

\section{INTRODUCTION}

Inflammation is the response to body aggression by a pathogen agent, an allergen, a toxic compound, a tissue lesion, etc. It is generally a phenomenon with fever and tiredness, with local symptoms, pain, and edema. During the inflammatory process, monocytes are rapidly recruited to the damaged or infected tissue, where they can differentiate into macrophages and leads to the regulated production of various pro- and anti-inflammatory mediators including cytokines, such as tumor necrosis factor- $\alpha$ (TNF- $\alpha$ ) and interleukins (IL-1 $\beta-2,-4,-6$, and -12), chemokines, such as neutrophil chemotactic factor IL-8, monocyte chemotactic and activating factor, transcription factors, such as nuclear factor- $\mathrm{\kappa B}(\mathrm{NF}-\mathrm{\kappa B})$ signal transducers and activators of transcription (STAT), protein kinases, such as mitogen-activated protein kinases (MAPK), methyl-accepting chemotaxis protein (MCP), macrophage migration inhibitory factor (MMF) and inducible enzymes, such as cyclooxygenase (COX-2), 5-lipoxygenase (5-LOX), inducible nitric oxide synthase (iNOS) [1-5]. Inflammation may be the cause of several chronic diseases such as arthritis, diabetes, obesity, cancer, neurodegenerative diseases, autoimmune disorders, dementia, scleroderma, allergy, asthma, bronchitis, inflammatory bowel disease, and cardiovascular diseases, which have been increased dramatically over the last three decades [6,7]. Non-elective nonsteroidal antiinflammatory drugs (NSAID) and COX-2 selective inhibitors are associated with various adverse effects, such as gastric ulceration, acute renal failure, and increased cardiovascular risk [8-11]. Hence, it is essential to find out newer drug leads for the treatment of inflammation.

\section{SINGLE NATURAL PRODUCTS WITH ANTI-INFLAMMATORY ACTIVITIES}

\section{Quercetin}

Quercetin, a naturally occurring polyphenol, found in a wide variety of food, such as, berries, broccoli, red onions, apples, grapevines and tea and have significant anti-inflammatory effects in both acute and chronic inflammatory conditions [12]. It inhibits the production of inflammation-producing enzymes (COX and LOX) [13]. Quercetin also exhibited protective effect against inflammation induced by hydrogen peroxide in human umbilical vein endothelial cells and indicated that the effect was mediated through the downregulation of vascular cell adhesion molecule 1 and CD80 expression [14]. Quercetin reduced inflammation in sarcoidosis patients by inhibiting the synthesis of proinflammatory cytokines, TNF- $\alpha$ and IL-8 [15]. Several recent clinical and preclinical findings suggest quercetin as a promising natural treatment for inflammatory skin diseases such as atopic dermatitis [16].

\section{Parthenolide}

Parthenolide, a sesquiterpene lactone, is extracted from the shoots of Tanacetum parthenium has been used to treat inflammatory conditions such as arthritis. It has NF- $\mathrm{KB}$ inhibiting properties in macrophage cell lines [17]. Studies are done on the parthenolide-depleted (PD) feverfew, which confirmed the inhibition of release of pro-inflammatory mediators such as TNF- $\alpha$, IL-2, IL-4 from human mononuclear cells, prostaglandin- $\mathrm{E}_{2}\left(\mathrm{PGE}_{2}\right)$, and NO. In addition, PD- feverfew inhibits the release of tissue plasminogen activator induced from human skin equivalents [18].

\section{Resveratrol}

Resveratrol, a stilbene derivative, can be found in peanuts, grapes, berries, and red wine [19]. It was found to have anti-inflammatory activity by activating peroxisome proliferator-activated receptor, endothelial NOS, and sirtuin-1 [20-22]. Resveratrol also inhibits the COX, NF- $\mathrm{KB}$, and phosphatidylinositol 3-kinase/Akt pathwas, which are involved in inflammation and many other diseases, such as various metabolic, neurodegenerative, and cardiovascular disorders. A lot of clinical trials have been reported on resveratrol, which are focused on inflammation associated disorders, many of them dealing with diabetes, obesity, cardiovascular diseases, topical diseases, cancer, and neurodegenerative diseases [23,24].

\section{Curcumin}

Curcumin is a polyphenol isolated from the rhizome of the plant Curcuma longa. It is the main ingredient of turmeric, the Indian spice, has been used for centuries in Ayurvedic medicine against inflammatory disorders. Curcumin exhibited anti-inflammatory property by the regulation of various molecular targets, including transcription factors (such as NK-кB), inflammatory cytokines (such as TNF- $\alpha$, IL-1 -2, -6, and -12), protein kinases (such as MAPK, and Akt, MCP, MMF) and other enzymes (such as COX-2 and 5-LOX, iNOS). Curcumin has been shown to be effective as anti-inflammatory/anti-rheumatic agent in some clinical trials $[2,3]$. 


\section{Cucurbitacin}

Cucurbitacin E (CE) was isolated fron Citrullus lanatus and the compound was examined for its anti-inflammatory action. Intraperitoneal injection of CE significantly suppressed carrageenan induced rat's paw edema. The result showed that CE is potentially useful in treating inflammation through the inhibition of COX and reactive nitrogen species. The compound showed more selectivity toward COX-2 [25]. Cucurbitacin IIb (CuIIb) is one of the major active compounds in hemsleyadine tablets which have been used for clinical treatment of enteritis and acute tonsillitis. CuIIb downregulated concanavalin A-induced STAT3 and NF- $\kappa$ B, phosphorylation in lymphocytes [26].

\section{Capsicin}

Capsaicin is a very hydrophobic alkaloid obtained from chili peppers (Capsicum species). A research on capsaicin reported that it acts against neuropathic pain by activating transient receptor potential channel vanilloid subfamily member 1 (TRPV1), a nonselective cation channel, mainly located in nociceptive neurons [27]. Prolonged activation of TRPV1 by capsaicin is discussed to cause desensitization and, thus, reduced pain sensation [28]. Capsaicin is effective in the management of osteoarthritis [29].

\section{1,8-Cineole}

1,8-cineole (eucalyptol) is a cyclic ether and a natural monoterpene, a major compound of many plant essential oils, mainly extracted from Eucalyptus globulus oil. 1,8-cineole has anti-inflammatory properties and based on this properties, recent clinical trials have shown the beneficial use of 1,8-cineole as long-term therapy in the prevention of chronic obstructive pulmonary diseases (COPD)-exacerbations and to improve asthma control [30,31]. As non-steroidal anti-inflammatory agent, 1,8-cineole can improve steroid effects when combined with budesonide and formoterol for asthma and COPD [32]. 1,8-cineole reduced lipopolysaccharide (LPS)-induced inflammation by inhibiting $\mathrm{NF}-\kappa \mathrm{B}$ in human cell lines U373 and HeLa [33].

\section{Bromelain}

Bromelain, an enzyme, was found in pineapple used as one of the most effective anti-inflammatory agents with adequate toxicology and safety testing data. The combination of bromelain and amenthoflavone exhibited a potential anti-inflammatory action by antagonising the Phoapholipase A2 [34]. Habashi et al. in 2016 studied the antiinflammatory properties of bromelain. The results showed that bromelain normalized the upregulated iNOS mRNA and inhibited NF$\kappa \mathrm{B}$ in microglial cells of rat [35].

\section{Boswellic acid (BA)}

BAs, pentacyclic triterpenic acids, were obtained from the resin of Boswellia serata. Among the various BAs $11 \beta$ - BA, acetyl- $\beta$-BA, 11-keto$\beta$-BA (KBA), and acetyl- KBA have been observed to be active as antiinflammatory agents and the most potent one was the acetyl- KBA. From the various studies, it was observed that BAs cause downregulation of TNF- $\alpha$ and decrease of IL-1, IL-2, IL-4, IL-6, interferon gamma, and inhibit 5-LOX [36,37]. Some derivatives of BA and KBA with wellknown anti-inflammatory drugs (i.e., aspirin, naproxen, ibuprofen and cinnamic acid) have been synthesized and evaluated for their anti-inflammatory and anti-arthritic activities. Among synthesized compounds, two compounds bearing naproxen and BA/KBA unit have displayed potent anti-inflammatory and anti-arthritic activities [38].

\section{Lyprinol}

Lyprinol is a lipid extract of the Perna canaliculus, which has been shown to be effective as anti-inflammatory agent in rats with carrageenaninduced pleurisy. The compound acted as dual inhibitors of COX and 5- LOX in vitro [39]. It has found to exhibit anti-arthritic activity [40].

\section{Coumarin}

Daphnetin, a coumarin derivative with analgesic and antiinflammatory effects, was extracted from Daphne odora and exhibited anti-arthritis effect in collagen-induced arthritis rat model through modulating the balance of T-regulatory and T-helper 17 [41]. Daphnetin also showed anti-inflammatory response in BV2 microglia by depressing the pro-inflammatory mediators (IL-1 $\beta$, TNF- $\alpha$ induced by LPS) and by inhibiting the LPS-induced iNOS and COX-2, NO formation by microglia [42]. Aurapten, another coumarin derivative isolated from Ferula szowitsiana and exhibited cancer chemopreventive properties suggested by anti-inflammatory activity of the compound [43]. Two coumarin derivatives, namely, 6-isopentenyloxy-7-methoxy-coumarin and 8-isopentenyloxy7-methoxy-coumarin, were isolated from Gerbera serrata and Haplophyllum pedicellatum, respectively, and investigated for antiinflammatory activity on U937-3xкB-LUC cell line. The compounds showed promising activity by inhibiting the LPS-induced NF- $\kappa B$ signalling pathway [44].

\section{NATURAL PLANT PRODUCTS WITH ANTI-INFLAMMATORY ACTIVITIES}

\section{Garlic (Allium sativum)}

The benefits of garlic to the human health have been promulgated for centuries. A. sativum is a plant from the genus allium is important for its production of organosulfur compounds having promising antiinflammatory activity [45]. Organosulfur compounds (Ajoene, diallyl sulfide, diallyl disulfide, allylmethyl sulfide, S-allyl cysteine, alliin, and allicin) were evaluated in various in vitro and in vivo animal models and also experimented in human volunteers for pre-clinical studies. These compounds inhibited LPS-induced inflammation by reduction in PGs, NO, IL-1 $\beta$, IL6 and TNF- $\alpha$ levels; increase in IL-10 levels; inhibition of COX-2, iNOS, and NF- $\kappa$ B activity [46].

\section{Ginger (Zingiber officinale)}

Ginger contains many active components of which gingerol, shogaol, and other structurally-related substances inhibit PG and leukotriene synthesis by suppressing the 5-LOX or PG synthetase. In addition, the fore-mentioned components also inhibit the synthesis of proinflammatory cytokines such as IL-8, IL-1, and TNF- $\alpha$. Gingerol and shogaol can also inhibit LPS-induced COX-2 [47]. Shimoda et al. studied red ginger extract (RGE) and found that the ethanolic extract had potential to inhibit $\mathrm{PGE}_{2}$ and $\mathrm{NO}$ in case of edema in rat models. RGE contains 6-shogaol, gingerdiols, and proanthocyanidins, are responsible for suppressing NO production [48].

\section{Papaya (Carica papaya)}

Papaya belonging to the family, Caricaceae, is grown in various parts of the world, including India, tropical America and Europe [49]. It contains papain, which is responsible anti-inflammatory action [50]. A report demonstrated the significant anti-inflammatory activity of papaya leaf juice (at $0.72 \mathrm{ml} / 100 \mathrm{~g}$ body weight) against carrageenaninduced rat paw edema [51]. Bertrand et al. in 2014 experimented on papaya extract to find out the anti-inflammatory activity and the extract showed reduction in TNF- $\alpha$ production in dependent manner [52].

\section{Blueberry (Vaccinium corymbosum)}

Blueberry contains a significant amount of flavonoids, specially anthocyanins, which are the active components possessing antiinflammatory action. Studies revealed that blueberry-enriched diet normalized the enhanced levels free radicals, gene and protein expression of inflammatory cytokines in post-traumatic stress disorder in rats [53]. Johnson et al. evaluated anti-inflammatory effect of anthocyanins and proanthocyanidins from fermented blueberryblackberry beverages and observed that the compounds reduced LPS-induced inflammation through NF- $\kappa \mathrm{B}$-mediated pathway in macrophages of mouse [54]. Huang et al. in 2014, had done a study to investigate the inhibitory effect of blueberry's two main anthocyanins known as malvidin-3-glucoside and malvidin-3-galactoside on inflammatory response in endothelial cells. They found thatmalvidin3-glucoside had better anti-inflammatory effect than malvidin-3galactoside and their anti-inflammation mechanism was mediated by the NF- $\kappa$ B pathway [55]. 


\section{Aloe (Aloe vera)}

Aloe has been used for millennium which is more like a cactus plant, growing in hot and dry climates, containing compounds such as aloe emodin, aloin, aloesin, saponins, and terpenoids that possess antiinflammatory actions [56]. The anti-inflammatory effects of aloe is due to the Salicylic acid which is the reason for the inhibition of formation of bradykinin and histamine and oxidation of arachidonic acid, which further is the reason for inhibition of PG synthesis [57].

\section{Broccoli (Brassica oleracea)}

The young broccoli sprouts contain bioactive compounds specifically sulforaphane, which has anti-inflammatory effect. Study showed that, sulforaphane, an isothiocyanate, decreased the concentration of $\mathrm{m}$-RNA of the pro-inflammatory cytokines TNF- $\alpha$ and IL- $1 \beta$ in murine RAW267.4 macrophages due to pro-inflammatory stimulus with bacterial LPS [58,59].

\section{Olive (Olea europaea)}

The phenolic extracts from virgin olive oil (VOO) are the focus of inflammation research as major product to fight against inflammatory diseases. Studies found out the VOO intake have markers on inflammation. Recent evidence has demonstrated that the VOO- phenolic extract potentially inhibits p-38 phosphorylation which results in reduction of COX-2 expression. The inflammatory pathways relevant to VOO, namely are the arachidonic pathway and the NF- $\mathrm{kB}[60]$. Oleocanthal, a polyphenolic natural compound from VOO, reported as a potential therapeutic agent for the treatment of inflammatory degenerative diseases. The anti-inflammatory activity of oleocanthal was associated with the inhibition of LPS-induced NO production in $\mathrm{J774}$ macrophages [61].

\section{Rosemary (Rosmarinus officinalis)}

Rosemary was found to have topical anti-inflammatory effect in mice [62]. Rosemary extract has shown gastroprotective effect against gastric ulcer due to its inhibition in neutrophils infiltration and reduction in proinflammatory mediators such as TNF- $\alpha$ and IL-1 [63]. The anti-inflammatory potential of rosemary is due to rosmarinic acid, which reduced rat paw edema over $60 \%$ at $6 \mathrm{~h}$ at the dose of $25 \mathrm{mg} / \mathrm{kg}$ [64]. In another study, rosmarinic acid was evaluated for its preventive activity in a murine model of asthma. Based on the results, it was concluded that the possible molecular mechanisms of rosmarinic acid might be mediated by the suppression of ERK, JNK, and p38 phosphorylation [65].

\section{NATURAL NON-PLANT PRODUCTS WITH ANTI-INFLAMMATORY ACTIVITIES}

\section{Marine sponges}

Very recently, Ahmad et al. isolated 6-bromoisatin from the Muricidae mollusk Dicathais orbita as potent anti-inflammatory agent. The compound reduced LPS-induced acute lung inflammation in a mouse model by inhibiting the production of TNF- $\alpha$ and IL-1 $\beta$ [66]. In 2015, some diterpenoids were isolated from marine source and their antiinflammatory activity has been shown to inhibit of NF-kB activation and to modulate of arachidonic acid metabolism [67].

\section{Mushrooms}

Elsayed et al. reported anti-inflammatory activities of mushrooms. Terpenoids, such as cyathins and related compounds, contained in these mushrooms are responsible for anti-inflammatory activity. They also suggested the mechanisms of action of the biologically active compounds. The compounds exhibited their anti-inflammatory effects due to reduction of IL- $1 \beta$, IL- 6 , LTs, PGs and TNF- $\alpha$ levels, and, inhibition of COX-2, iNOS and NFKB activity [68]. The ethanolic extract of mushroom was assessed on stimulation of RAW264.7 macrophages for the production of the inflammatory mediator NO with liposaccharide for the anti-inflammatory action. The anti-inflammatory function of mushroom extracts is related to the potential of inhibition of specific steps leading to the NF-KB release [69]. Jedinak et al. in in 2011 did research on oyster mushroom concentrate (OMC), which on treatment suppressed the LPS-dependent production of TNF- $\alpha$, IL- 6 and IL-12 in a dose-response manner. The effect was not caused by the cytotoxicity of OMC as OMC did not affect viability of RAW264.7 cells. Only slight inhibition of cell viability was seen. Therefore, the anti-inflammatory action of OMC is by the inhibition of production of TNF- $\alpha$, IL- 6 and IL$12[70]$.

\section{Honey}

Honey reduced inflammatory response not only in animal models and cell cultures but also in clinical trials [71]. Phenols and flavonoids present in honey are responsible for anti-inflammatory activity. These compounds were involved in regulation of proteins including of iNOS, ornithine decarboxylase, tyrosine kinase, and COX-2. Honey

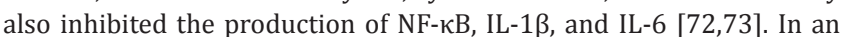
inflammatory model of colitis, honey was as effective as prednisolone treatment, without the major side effects associated with NSAIDs and corticosteroids [74].

\section{CONCLUSION}

Nature is a rich source for the development of novel lead as antiinflammatory agent. Current interest will lead the researchers to search for new natural products with anti-inflammatory activity. It is very probable that in the coming years, more novel products will get entry into the commercial market. Based on the literature survey, we are concluding that, there are very less or no side effects of the above mentioned anti-inflammatory natural drugs. Furthermore, these are not only the ones having anti-inflammatory effects; however, there are a number of known natural products having anti-inflammatory effect and few are under research. To date, clinical trials conducted with antiinflammatory natural products are very limited. A few of the above mentioned single natural compounds, such as quercetin, curcumin, resveratrol, CuIIb, and non-plant products, such as honey have been reached in clinical trials against inflammation. Hence, more clinical trials are necessary for the safety and efficacy of natural products, to bring them in the market as anti-inflammatory drug, either alone or in combination with other anti-inflammatory agents.

\section{AUTHORS CONTRIBUTIONS}

All the authors have contributed equally.

\section{CONFLICTS OF INTEREST}

The authors declare no conflict of interest.

\section{ABBREVIATIONS}

AD: Atopic dermatitis

COPD: Chronic obstructive pulmonary disease

COX: Cyclooxygenase

eNOS: Endothelial nitric oxide synthase

$\mathrm{H}_{2} \mathrm{O}_{2}$ : Hydrogen peroxide

iNOS: Inducible nitric oxide synthase

IL: Interleukin

IFN $\gamma$ : Interferon gamma

LOX: Lipoxygenase

MAPK: Mitogen-activated protein kinase

MCP: Methyl-accepting chemotaxis protein

MMF: Macrophage migration inhibitory factor

$\mathrm{NF} \kappa \mathrm{B}$ : Nuclear factor $\kappa \mathrm{B}$

NO: Nitric oxide

PI3K: Phosphatidylinositol 3-kinase

PTSD: Post-Traumatic Stress Disorder

PPAR: Peroxisome proliferator-activated receptor

PGE $_{2}$ : Prostaglandin- $\mathrm{E}_{2}$

RNS: Reactive nitrogen species

SIRT: Sirtuin

STAT: Signal transducer and activator of transcription

VCAM: Vascular cell adhesion molecule

TNF: Tumor necrosis factor 
Tregs: T-regulatory

Th17: T-helper 17

TPA: Ttissue plasminogen activator

TRPV1: Transient receptor potential channel vanilloid subfamily member 1

\section{REFERENCES}

1. Latruffe M. Natural products and inflammation. Molecules 2017;22:1-3.

2. Matthew F, Cecilia L, Jai B, Henry TL. Curcumin: An age-old anti-inflammatory and anti-neoplastic agent. J Trad Comp Med 2017;7:339-46.

3. Zhou H, Beevers CS, Huang S. The targets of curcumin. Curr Drug Targets 2011;12:332-47

4. Matsushima K, Terashima Y, Toda E, Shand F, Ueha S. Chemokines in inflammatory and immune diseases. Inflamm Regen 2011;31:11-22.

5. Lawrence T, Fong C. The resolution of inflammation: Anti-inflammatory roles for NF-kappa B. Int J Biochem Cell Biol 2010;42:519-23.

6. Bosma-den Boer MM, van Wetten ML, Pruimboom L. Chronic inflammatory diseases are stimulated by current lifestyle: How diet, stress levels and medication prevent our body from recovering. Nutr Metab 2012;9:32.

7. He Y, Yue Y, Zheng X, Zhang K, Chen S, Du Z. Curcumin, inflammation, and chronic diseases: How are they linked? Molecules 2015;20:9183-213

8. Mandal SK, Ray SM. Synthesis and biological evaluation of (5, 6-dialkoxy-3-oxo-2,3dihydro $1 H$-inden-1-yl)acetic acid esters as anti- inflammatory agents with much reduced gastrointestinal ulcerogenic potential. Indo Am J Pharm Res 2014;4:3796-807.

9. Lanas A. A review of the gastrointestinal safety data-a gastroenterologist's perspective. Rheumatology 2010;49:ii3-10.

10. Vishwanathan B, Gurupadayya BM, Sairam KV, Inturi BK. Design, synthesis, in vitro antioxidant and in vivo anti-inflammatory activities of novel oxadiazole derivatives. Int J Pharm Pharm Sci 2014;6:514-20.

11. Mandal SK, Ray SM. Synthesis and biological evaluation of (6-chloro-3-oxo-2,3- dihydro $1 H$-inden-1-yl)acetic acid esters as antiinflammatory agents devoid of ulcerogenic potential at the tested dose level. Indo Am J Pharm Res 2014;4:343-50.

12. Kaidama WM, Gacche RN. Anti-inflammatory activity of quercetin in acute and chronic phases of inflammation in guinea pigs. Am J Phy Clin Ther 2015;3:129-36.

13. Lee KM, Hwang MK, Lee DE, Lee KW, Lee HJ. Protective effect of quercetin against arsenite-induced COX-2 expression by targeting PI3K in rat liver epithelial cells. J Agric Food Chem 2010;58:5815-20.

14. Yang D, Liu X, Liu M, Chi H, Liu J, Han H. Protective effects of quercetin and taraxasterol against $\mathrm{H}_{2} \mathrm{O}_{2}$-induced human umbilical vein endothelial cell injury in vitro. Exp Ther Med 2015;10:1253-60.

15. Boots AW, Drent M, de Boer VC, Bast A, Haenen GR. Quercetin reduces markers of oxidative stress and inflammation in sarcoidosis. Clin Nutr 2011;30:506-12.

16. Karuppagounder V, Arumugam S, Thandavarayan RA, Sreedhar R, Giridharan VV, Watanabe K. Molecular targets of quercetin with anti-inflammatory properties in atopic dermatitis. Drug Discov Today 2016;21:632-9.

17. Xhang X, Fan C, Xiao Y, Mao X. Anti-inflammatory and antiosteoclastogenic activities of parthenolide on human periodontal ligament cells in vitro. Evid Based Complement Altern Med 2014;2014:1-11.

18. Sur R, Martin K, Liebel F, Lyte P, Shapiro S, Southali M. Anti-inflammatory activity of parthenolide-depleted feverfew. Inflammopharmacology 2009; 17:42-9.

19. Campagna M, Rivas C. Antiviral activity of resveratrol. Biochem Soc Trans 2010;38:50-3

20. Chung S, Yao H, Caito S, Hwang JW, Arunachalam G, Rahman I. Regulation of SIRT1 in cellular functions: Role of polyphenols. Arch Biochem Biophys 2010;501:79-90

21. Nakata R, Takahashi S, Inoue $\mathrm{H}$. Recent advances in the study on resveratrol. Biol Pharm Bull 2012;35:273-9.

22. Schmitt CA, Dirsch VM. Modulation of endothelial nitric oxide by plant-derived products. Nitric Oxide 2009;21:77-91

23. Wahab A, Gao K, Jia C, Zhang F, Tian G, Murtaza G, et al. Significance of resveratrol in clinical management of chronic diseases. Molecules 2017;22:1329

24. Berman AY, Motechin RA, Wiesenfeld MY, Holz MK. The therapeutic potential of resveratrol: A review of clinical trials. NPJ Precis Oncol 2017;1:1-17

25. Abdelwahab SI, Hassan LE, Sirat HM, Yagi SM, Koko WS, Mohan S, et al. Anti-inflammatory activities of cucurbitacin $\mathrm{E}$ isolated from Citrullus lanatus variety citroides. Fitoterapia 2011;82:1190-7.

26. Wang Y, Zhao GX, Xu LH, Liu KP, Pan H, He J, et al. Cucurbitacin $\mathrm{IIb}$ exhibits anti-inflammatory activity through modulating multiple cellular behaviours of mouse lymphocytes. PLoS One 2014;9:e89751.

27. O'Neill J, Brock C, Olesen AE, Andresen T, Nilsson M, Dickenson AH. Unravelling the mystery of capsaicin: A tool to understand and treat pain. Pharmacol Rev 2012;64:939-71.

28. Haanpaa M, Treede RD. Capsaicin for neuropathic pain: Linking traditional medicine and molecular biology. Eur Neurol 2012;68:264-75.

29. De Silva V, El-Metwally A, Ernst E, Lewith G, Macfarlane GJ. Evidence for the efficacy of complementary and alternative medicines in the management of osteoarthritis: A systematic review. Rheumatology 2011;50:911-20.

30. Bhowal M, Gopal M. Eucalyptol: Safety and pharmacological profile. RGUHS J Pharm Sci 2015;5:126-41.

31. Juergens UR. Anti-inflammatory properties of the monoterpene 1.8-cineole: Current evidence for co-medication in inflammatory airway diseases. Drug Res 2014;64:638-46.

32. Juergens LJ, Racké K, Tuleta I, Stoeber M, Juergens UR. Antiinflammatory effects of 1, 8-cineole (eucalyptol) improve glucocorticoid effects in vitro: A novel approach of steroid-sparing add-on therapy for COPD and asthma? Synergy 2017;5:1-8.

33. Greiner JF, Müller J, Zeuner MT, Hauser S, Seidel T, Klenke C, et al. 1, 8-Cineol inhibits nuclear translocation of NF-kB p65 and NF-kB-dependent transcriptional activity. Biochim Biophys Acta 2013;1833:2866-78

34. Tap FM, Majid FA, Ismail HF, Wong TS, Shameli K, Miyake M, et al. In silico and in vitro study of the bromelain-phytochemical complex inhibition of phospholipase A2 (PLA2). Molecules 2018;23:1-13.

35. Habashi SA, Sabouni F, Moghimi A, Majd SA. Modulation of lipopolysaccharidestimulated nuclear factor kappa B mediated iNOS/ NO productionby bromelain in rat primary microglial cells. Iran Biomed J 2016;20:33-40.

36. Ammon HP. Modulation of the immune system by Boswellia serrata extractsand boswellic acids. Phytomedicine 2010;17:862-7.

37. Sididiqui MZ. Boswellia serrata, a potential anti inflammatory agent, a review. Ind J Pharm Sci 2011;73:261-6.

38. Chaturvedi AK, Mishra N, Siddiqui HH, Mishra V. Semisynthetic hybrids of boswellic acids: A novel class of potential anti-inflammatory and anti-arthritic agents. Med Chem Res 2015;24:2799-812.

39. Calzado YR, Cuevas VM, Guerra YP, Yera AO, Despaine SJ, Ferreiro RM. Anti-edema effects of D-002 and lyprinol on the carrageenan-induced pleurisy in rats. Int $\mathrm{J}$ Pharm Sci Rev Res 2013;23:24-8

40. Doggrell SA. Lyprinol-is it a useful anti-inflammatory agent? Evid Based Complement Altern Med 2011;2011. Article ID: 307121:1-7.

41. Yao R, Fu Y, Li S, Tu L, Zeng X, Kuang N. Regulatory effect of daphnetin, a coumarin extracted from Daphne odora, on the balance of Treg and Th17 in collagen-induced arthritis. Eur J Pharmacol 2011;670:286-94.

42. Yu W, Wang H, Ying H, Yu Y, Chen D, Ge W, et al. Daphnetin attenuates microglial activation and proinflammatory factor production via multiple signaling pathways. Int Immunopharmacol 2014;21:1-9.

43. Gholami O, Shamsara J. Comparison of the cytotoxic effects of umbelliprenin and auraptene. Int J Pharm Pharm Sci 2015;8:1-4

44. Azelmat J, Fiorito S, Taddeo VA, Genovese S, Epifano F, Grenier D. Synthesis and evaluation of antibacterial and anti-inflammatory properties of naturally occurring coumarins. Phytochem Lett 2015;13:399-405.

45. Arreola R, Quintero-Fabián S, López-Roa RI, Flores-Gutiérrez EO, Reyes-Grajed JP, Carrera-Quintanar L, et al. Immunomodulation and anti-inflammatory effects of garlic compounds. J Immunol Res 2015;2015. Article ID 401630:1-13.

46. Schäfer G, Kaschula $\mathrm{CH}$. The immunomodulation and antiinflammatory effects of garlic organosulfur compounds in cancer chemoprevention. Anti Cancer Agents Med Chem 2014;14:233-40.

47. Mashhadi NS, Ghiavsand R, Askari G, Hariri M, Darvishi L, Mofid MR. Anti-oxidative and anti-inflammatory effects of ginger in health and physical activity: Review of current evidence. Int J Prev Med 2013;4:S36-42.

48. Shimoda H, Shan SJ, Tanaka J, Seki A, Seo JW, Kasajima N, et al. Antiinflammatory properties of red ginger (Zingiber officinale var. Rubra) extract and suppression of nitric oxide production by its constituents. J Med Food 2010;13:156-62

49. Milind P, Gurditta. Basketful benefits of Papaya. Int Res J Pharm $2011 ; 2: 6-12$ 
50. Amri E, Mamboya F. Papain, a plant enzyme of biological importance: A review. Am J Biochem Biotech 2012;8:99-104.

51. Pandey S, Cabot PJ, Shaw PN, Hewavitharana AK. Anti-inflammatory and immune-modulatory properties of Carica papaya. J Immunotoxicol 2016;13:590-602.

52. Bertrand S, Donatella F, Rita C, Carla M, Giancarlo F, Vittorio C. Anti-oxidant and anti-inflammatory activities of extracts from Cassia alata, Eleusine indica, Eremomastax speciosa, Carica papaya and Polyscias fulva medicinal plants collected in Cameroon. PLoS One 2014;9:e103999.

53. Ebenezer PJ, Wilson CB, Wilson LD, Nair AR, Francis J. The antiinflammatory effects of blueberries in an animal model of posttraumatic stress disorder (PTSD). PLoS One 2016;11:e0160923.

54. Johnson MH, de Meija EG, Fan J, Lila MA, Yousef GG. Anthocyanins and proanthocyanidins from blueberry-blackberry fermented beverages inhibit markers of inflammation in macrophages and carbohydrateutilizing enzymes in vitro. Mol Nutr Food Res 2013;57:1182-97.

55. Huang WY, Liu YM, Wang J, Wang XN, Li CY. Anti-inflammatory effect of the blueberry anthocyanins malvidin-3-glucoside and malvidin3-galactoside in endothelial cells. Molecules 2014;19:12827-41.

56. Jiang M, Deng K, Jiang C, Fu M, Guo C, Wang X, et al. Evaluation of the antioxidative, antibacterial, and anti-inflammatory effects of the aloe fermentation supernatant containing lactobacillus plantarum HM218749.1. Mediators Inflamm 2016;2016. Article ID: 2945650:1-8.

57. Eghdampour F, Fereshteh J, Khyerkhah M, Taghizadeh M, Naghizadeh S, Hagini H. The impact of Aloe vera and calendula on perineal healing after episiotomy in primiparous women: A randomized clinical trial. J Caring Sci 2013;2:279-86.

58. Bahadoran Z, Mirmiran P, Azizi F. Potential efficacy of broccoli sprouts as a unique supplement for management of Type 2 diabetes and its complications. J Med Food 2013;16:375-82.

59. Hwang JH, Lim SB. Antioxidant and anti-inflammatory activities of broccoli florets in LPS-stimulated RAW 264.7 cells. Prev Nutr Food Sci 2014;19:89-97.

60. Parkinson L, Russell A, Keast R. Molecular mechanisms of inflammation. Anti-inflammatory benefits of virgin olive oil and the phenolic compound oleocanthal. Curr Pharm Des 2011;17:754-68

61. Scotece M, Gomez R, Conde J, Lopez V, Gomez-Reino JJ, Lago F, et al. further evidence for the anti-inflammatory activity of Oleo canthal: Inhibition of MIP-1 $\alpha$ and IL-6 in J774 macrophages and in ATDC5 chondrocytes. Life Sci 2012;91:1229-35.

62. Abu-Al-Basal MA. Healing potential of Rosmarinus officinalis L. on full-thickness excision cutaneous wounds in alloxan-induced diabetic BALB/c mice. J Ethnopharmacol 2010;131:443-50.

63. Amaral GP, De Carvalho NR, Barcelos RP, Dobrachinski F, De Lima Portella R, Da Silva MH, et al. Protective action of ethanolic extract of Rosmarinus officinalis L. in gastric ulcer prevention induced by ethanol in rats. Food Chem Toxicol 2013;55:48-55.

64. Rocha J, Eduardo-Figueira M, Barateiro A, Fernandes A, Brites D, Bronze R, et al. Anti-inflammatory effect of rosmarinic acid and an extract of Rosmarinus officinalis in rat models of local and systemic inflammation. Basic Clin Pharmacol Toxicol 2015;116:398-413.

65. Liang Z, Xu Y, Wen X, Nie H, Hu T, Yang X, et al. Rosmarinic acid attenuates airway inflammation and hyper responsiveness in a murine model of asthma. Molecules 2016;21:769.

66. Ahmad TB, Rudd D, Benkendorff K, Mahdi LK, Pratt KA, Dooley L, et al. Brominated indoles from a marine mollusc inhibit inflammation in a murine model of acute lung injury. PLoS One 2017;12:2-3.

67. Gonzalez Y, Torres-Mendoza D, Jones GE, Fernandez PL. Marine diterpenoids as potential anti-inflammatory agents. Mediat Inflamm 2015;2015. Article ID: 263543:1-14.

68. Elsayed EA, El Enshasy H, Wadaan MA, Aziz R. Mushrooms: A potential natural source of anti-inflammatory compounds for medical applications. Mediat Inflamm 2014;2014. Article ID: 805841:1-15.

69. Taofiq O, Helena AS, Calhela CR, Alves MJ, Barros L, Barreiro FM, et al. Development of mushroom-based cosmeceutical formulations with anti-inflammatory, anti-tyrosinase, antioxidant, and antibacterial properties. Molecules 2016;21:3-12.

70. Jedinak A, Dudhgoankar S, Wu Q, Simon J, Sliva D. Anti-inflammatory activity of edible oyster mushroom is mediated through the inhibition of NF-B and AP-1 signaling. Nutr J 2011;10:52.

71. Leong AG, Herst PM, Harper JL. Indigenous New Zealand honeys exhibit multiple anti-inflammatory activities. Innate Immun 201218:459-66.

72. Araâjo JR, Gonçalves P, Martel F. Chemopreventive effect of dietary polyphenols in colorectal cancer cell lines. Nutr Res 2011;31:77-87.

73. Hussein SZ, Yusoff KM, Makpol S, Yusof YA. Gelam honey inhibits the production of proinflammatory, mediators NO, PGE (2), TNF-a, and IL-6 in carrageenan-induced acute paw edema in rats. Evid Based Complement Alternat Med 2012;2012. Article ID: 109636,1-13.

74. Himaya SW, Ryu B, Qian ZJ, Li Y, Kim SK. 1-(5-bromo-2-hydroxy4-methoxyphenyl) ethanone [SE1] suppresses pro-inflammatory responses by blocking $\mathrm{NF}-\mathrm{\kappa B}$ and MAPK signaling pathways in activated microglia. Eur J Pharmacol 2011;670:608-16. 